\title{
Large Scale Desalination: A Comparative Cost Affective Economic Analyses of Nuclear, Gas and Solar Powered Plants
}

\author{
Mohammed H. S. Al Ashry',2 \\ ${ }^{1}$ Department of Computer Science, the Community College, Shaqra University, Shaqra, Saudi Arabia \\ ${ }^{2}$ Department of Computer Science, the College of Sciences and Humanities, Shaqra University, Shaqra, \\ Saudi Arabia \\ Email: mashry@su.edu.sa
}

Received 23 January 2015; accepted 9 February 2015; published 13 February 2015

Copyright (C) 2015 by author and Scientific Research Publishing Inc.

This work is licensed under the Creative Commons Attribution International License (CC BY). http://creativecommons.org/licenses/by/4.0/

(c) (i) Open Access

\section{Abstract}

The main objective, here, is to explore the economic viability of the solar powered desalination method through a cost and benefit comparative and contrast study. Using the initial construction expenditure, the annual maintenance cost and energy consumed or produced, a variance ratio test of the random walk hypothesis will be implemented to determine their relative financial efficiency. This paper will also utilize the first order autoregressive multivariate estimation model to analyze the methods and identify the most productive process with most financial promise for future investment. The total deviations of the estimated variables from the actual are accounted for by the variations of the variances of the estimates from the actual. The higher the percentage of the unexplained deviation, the higher the risk involved. The portfolio variance will be utilized to measure the investment risk in three desalination industries.

\section{Keywords}

System's Lifecycle: The Time after Which the System Become a Liability, Heteroscedasticity: Different Sampling Variables, Autoregressive: Descriptive Estimates of Random Variables, Asymptotic: A Line Infinitely Approaching another Curve-Linear Line(s)

\section{Introduction}

Water is probably the most important commodity affecting the livelihoods of the majority of the populations on the Earth. In due course, water will be at the central stage of a worldwide crisis that may consume millions of How to cite this paper: Al Ashry, M.H.S. (2015) Large Scale Desalination: A Comparative Cost Affective Economic Analyses of Nuclear, Gas and Solar Powered Plants. Theoretical Economics Letters, 5, 103-113. 
lives. It is imperative to find the least expensive and most productive approach to largely produce water in order to satisfy the future needs of the Earth's inhabitants. Not much literature is written on direct solar energy for the purpose of producing drinking water, not on a large scale anyway.

The nuclear, gas and solar energy schemes differ in the technique to produce energy [1] [2], however, there are few viable options to produce drinking water. In this paper only the Multi-Stage-Flash (MSF) system is considered for the desalination of seawater [3]. MSF uses a process in which seawater is heated, evaporated and then condensed to produce drinking water. For the nuclear and gas plants, the water, on average, is heated to boiling temperature, $100^{\circ} \mathrm{C}-105^{\circ} \mathrm{C}$, to increase the percentage of the evaporated water, which in turn increases the percentage of condensed water. However, the downside, in this case, is that increasing the heated water temperature, in the long run, lowers the efficiency of MSF system, and reduces the span of the system's lifecycle. This increases cost and lowers its investment potential. The direct solar heat, on the other hand, heats the seawater in long parallel ducts (Figure 1) to a reasonable temperature subject to the location and seasonal temperature variations. In Saudi Arabia the water collectors' temperature averages about $80^{\circ} \mathrm{C}$ for the solar-heated seawater during the days of the summer months [4]. The average temperature difference between the seawater and the seaside ground surface fluctuates for nights and days, winters to summers periods, $30^{\circ} \mathrm{C}$ to $50^{\circ} \mathrm{C}$, respectively [4]. This increases the evaporation and condensation during the summer period, however, the temperature interval separating the lows and highs during the rest of the year is enough for the production of large amounts of drinking water [3] [4].

In Saudi Arabia a large number of gas-powered seawater desalination plants are operating, being built, or planned. Due to the scarcity of water in the Arabian Peninsula, Saudi Arabia may rely on seawater desalination for a long time to come. However, it is worth mentioning that in the long run, although not economically proven feasible, some believe that nuclear energy may be the most reliable for producing and desalinating electricity and sea water, respectively [5] [6].

The data can be divided into informational data such as the cost of energy, operation and maintenance (O \& M) per million joules (MJ), and the cost of construction is also the same. This information is used to calculate the total cost per million joules (TC/MJ) of energy [1]. Maintenance includes energy, labor, parts and other indirect costs. Construction includes, for nuclear power, nuclear reactors, turbines, heaters, all other required plant's concrete chamber(s), compressors, gauges and monitors; for gas power, all of the above are included, excluding the nuclear reactor and adding the gas-based electric turbines [7].

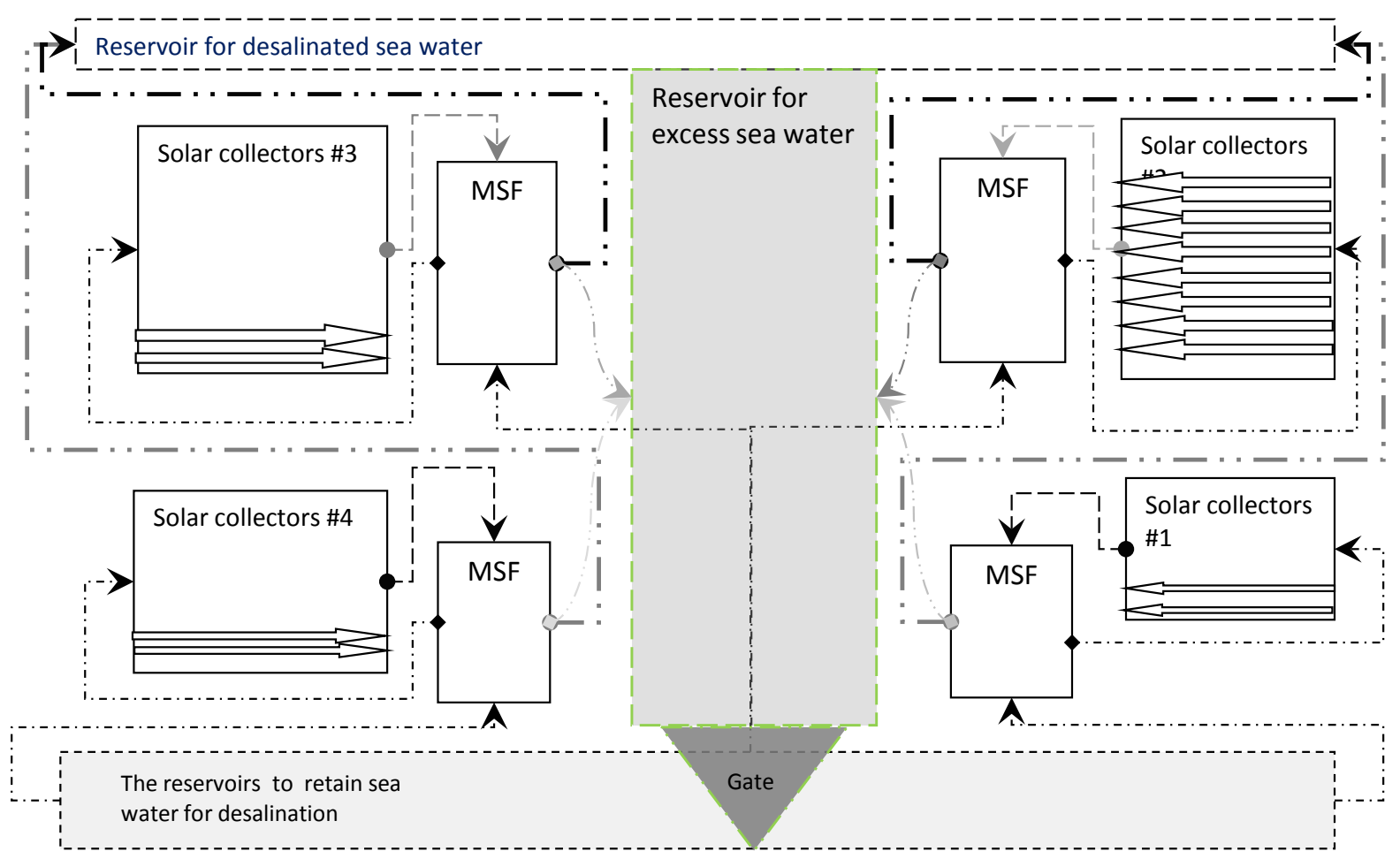

Figure 1. The tide-based seawater desalination system (Ashry, Mohammed H., Csrea Press, 2013). 


\section{Defining the Parameters}

The data for the nuclear and gas energy based plants are extracted from US energy production costs between 1995 and 2011. The previous three years are the result of a regressive inflation based extrapolation [1] [2]. However, the solar powered plant's data are entirely inflation-based extrapolated estimates [7]. TC/MJ is utilized for two purposes:

a) To calculate the profit under the assumption that the initial cost is financed. In this case the cost of the first year is multiplied by 2000 to obtain the present worth (PW) of the financing money for the establishment of two Giga Joules energy-plant for the production of drinking water. The annual payment (AP) and the future worth (FW) of the borrowed money are calculated at the bottom of Table 1 or each of the industrial sectors; however, only Table 1 will be discussed, since all the figures and the table follow the same mathematical procedure, except for the solar energy where the data are extracted entirely, as mentioned above, from inflation based data, and which is the main subject of this paper. The total cost of two Giga Joules energy-plant will be used as the present worth of the project to estimate and gauge their future value over twenty years. The first year, 1992, will be used to calculate the present worth-value to finance the project. The financing data will be used purely for comparative purposes with the actual data and its estimates to emphasize the viability of the marketing future of the desalination industry.

b) The actual total of the varying inflation-based cost [8] will be calculated by tallying the cost of the first year, 1992, plus the aggregate portions greater than the 1992-magnitude, for the duration of the time series to 2011. With the exception of the nuclear sector, both the gas-based and the direct sun-radiation energy-based sectors fluctuate above and below the 1992 magnitude, due to many factors which will be discussed later. The future value of the actual total cost is displayed in Row 25, under the heading "Actual Total Project Cost/Million Joules, (ATC/MJ)", in Table 1, for the three sectors, respectively, where $T_{i}=\left[\left(R_{i} * 2000\right)+\Sigma\left(R_{i j}-R_{i}\right)\right]$ for $i=1$ and $j=i, \cdots, n$; where $i, \cdots, n$ stands for the magnitudes of 1992-2011. These values for the three sectors are also solely as reference and for comparative purposes. The actual market rates' time series values for the three sectors, "revenue data" ( $R_{1}, R_{2}$ and $R_{3}$ ), will be estimated using the first order autoregressive model (FOA) to estimate $\check{R}_{1}, \breve{R}_{2}$ and $\breve{R}_{3}$ [9]. The actual and estimated values will be utilized to run a variance ratio test of the random walk hypothesis of both variances (Table 2), $\operatorname{VR}\left(q_{a}\right)$ and $V R\left(q_{e}\right)$, where a stands for actual and $e$ for estimated. This is employed to assess the viability of the energy producing schemes including the solar seawater desalination. The data in turn can be evaluated using the variances and data fluctuations of the three energy schemes. The objective is to forecast the viability of the solar energy for seawater desalination. The notion that annual changes in the cost of energy-projects including desalination are equivalent to changes in stocks' earning yields is adopted to facilitate the process. The stocks of the involved manufacturing businesses are rising due to people's growing need for drinking water. The increasing cost of seawater-desalination projects is due to both the rising cost of the energy and the emergence of numerous and diverse advances in desalination technology that have not been extensively tested, despite its competitive market. Energy projects for water desalination are investments known for its high return, however the risk associated with such projects adds to the uncertainty of the seawater desalination ventures in general. Solar seawater desalination eliminates this uncertainty [4]. The cost-effectiveness and efficiency of the desalination of seawater through direct solar energy is an asset that someday will provide the world with most of its drinking water.

\section{Application Analysis}

The schemes employed are intended to test for the most appropriate energy based process for global mass water-production. In this paper, the total per energy cost of the construction, operation and maintenance is subject to changing inflation, depreciation, and rate changes in the cost of material due to constantly changing technology. However, the cost is actually an investment, part of which is earnings to investors; which maybe a cost to the project's owners hoping to make a profit on the long run. There are three parties involved here, the manufacturers, for whom the project is revenue, the banks or investors providing the loan, and the owners operating or leasing the finished project for profit. The first year's Cost/MJ of energy is used as the base value to calculate the present value of the investment. The financing uses this value to calculate the annual payment and future value of the investment after twenty years with a 3\% interest rate, purely for economic comparison purposes. The calculated future values (FW), as shown in Table 1, for the solar case, with annual principle payment AP1, 


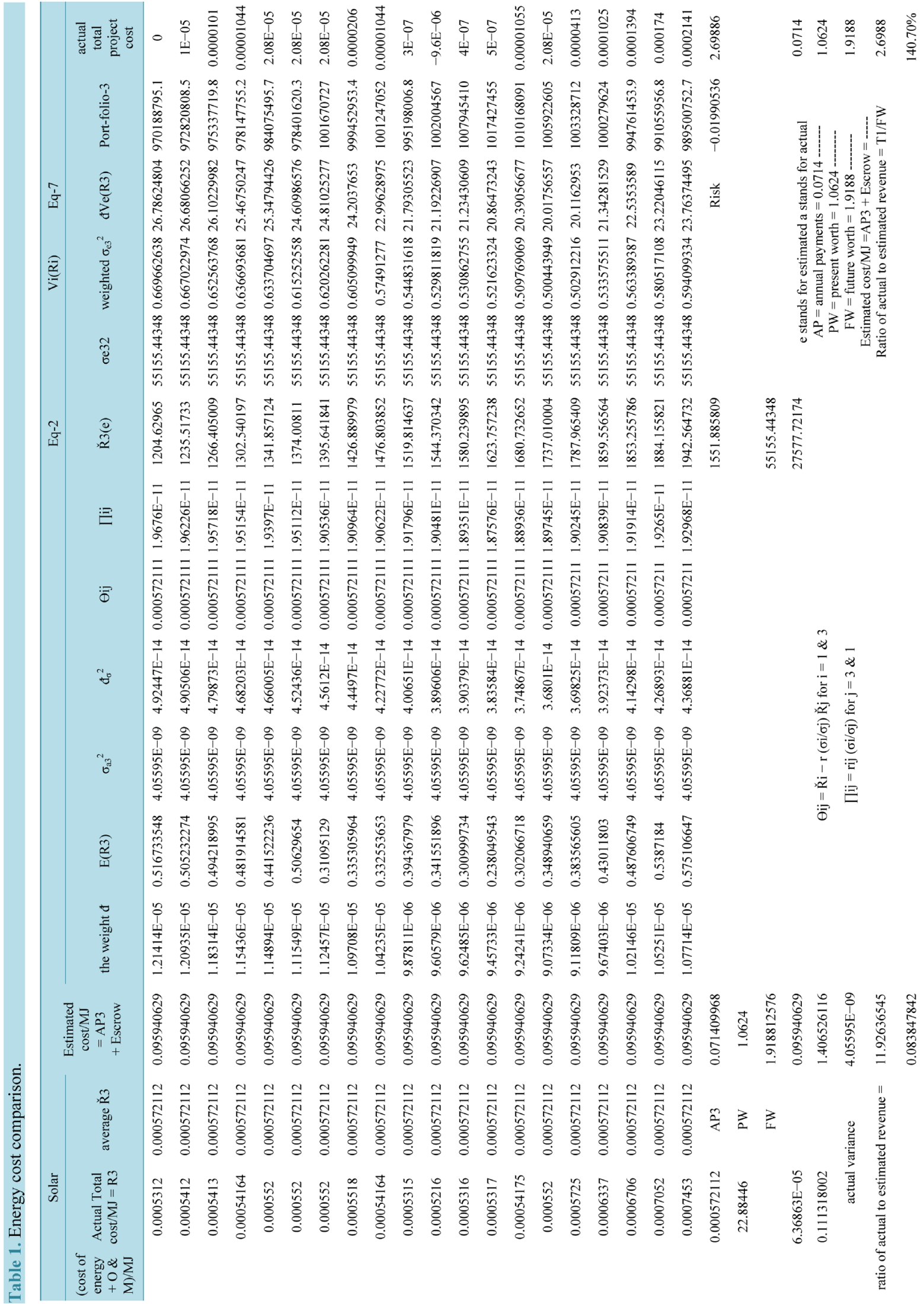




\begin{tabular}{|c|c|c|c|c|c|c|c|c|}
\hline \multirow[t]{2}{*}{ Factors } & & \multirow{2}{*}{$\begin{array}{c}\text { Total cost/MJ } \\
\text { actual }\end{array}$} & \multirow{2}{*}{$\begin{array}{c}\text { Total cost/MJ } \\
\text { estimated }\end{array}$} & \multirow{2}{*}{ Total cost/MJ } & \multirow{2}{*}{ Total cost/MJ } & & \multirow{2}{*}{$\begin{array}{c}\text { heteroscedistic } \\
\text { asymptotic } \\
\text { variance (HAV) }\end{array}$} & \multirow[t]{2}{*}{ Z-test } \\
\hline & & & & & & $\mathrm{VR}(\mathrm{q}) \mathrm{a}$ & & \\
\hline Time $\downarrow$ & Fuel $\rightarrow$ & $\mathrm{Xt}=\mathrm{R} 1: \mathrm{R} 3$ & $\mathrm{Xt}(\mathrm{e})=\mathrm{R} 1: \mathrm{R} 3$ & $(\mathrm{Xt}-\mathrm{q}) \mathrm{a}$ & $(X t-q) e$ & $\mathrm{~V}(\mathrm{Xt}-\mathrm{k}) / \mathrm{V}(\mathrm{Xt})$ & $v^{*}(k) a$ & $\mathrm{Z}^{*}(\mathrm{k}) \mathrm{a}$ \\
\hline 1992 & & $3.9000 \mathrm{E}+01$ & $1.1116 \mathrm{E}+03$ & $4.1000 \mathrm{E}+01$ & $1.3701 \mathrm{E}+08$ & 0.966356446 & $3.84329 \mathrm{E}+18$ & $-4.38 \mathrm{E}-21$ \\
\hline 1993 & & $4.0000 \mathrm{E}+01$ & $1.1424 \mathrm{E}+03$ & $4.4484 \mathrm{E}+01$ & $1.4422 \mathrm{E}+08$ & & & \\
\hline 1994 & & $4.1000 \mathrm{E}+01$ & $1.1733 \mathrm{E}+03$ & $4.7812 \mathrm{E}+01$ & $1.1972 \mathrm{E}+08$ & & & \\
\hline 1995 & & $4.2170 \mathrm{E}+01$ & $1.2095 \mathrm{E}+03$ & $5.1161 \mathrm{E}+01$ & $1.1741 \mathrm{E}+08$ & $\operatorname{VR}(q) e$ & $v^{*}(k) e$ & $\mathrm{Z}^{*}(\mathrm{k}) \mathrm{e}$ \\
\hline 1996 & & $4.3443 \mathrm{E}+01$ & $1.2487 \mathrm{E}+03$ & $5.6236 \mathrm{E}+01$ & $1.3269 \mathrm{E}+08$ & 0.998432606 & $2.15787 \mathrm{E}+17$ & $-7.5 \mathrm{E}-20$ \\
\hline 1997 & & $4.4484 \mathrm{E}+01$ & $1.2811 \mathrm{E}+03$ & $6.0000 \mathrm{E}+01$ & $1.6298 \mathrm{E}+08$ & & & \\
\hline 1998 & & $4.5184 \mathrm{E}+01$ & $1.3021 \mathrm{E}+03$ & $4.7504 \mathrm{E}+00$ & $1.3699 \mathrm{E}+08$ & & & \\
\hline 1999 & & $4.6196 \mathrm{E}+01$ & $1.3335 \mathrm{E}+03$ & $4.7504 \mathrm{E}+00$ & $1.3699 \mathrm{E}+08$ & & & \\
\hline 2000 & & $4.7812 \mathrm{E}+01$ & $1.3834 \mathrm{E}+03$ & $3.9004 \mathrm{E}+00$ & $1.1248 \mathrm{E}+08$ & & & \\
\hline 2001 & & $4.9205 \mathrm{E}+01$ & $1.4267 \mathrm{E}+03$ & $4.6008 \mathrm{E}+00$ & $1.3268 \mathrm{E}+08$ & & & \\
\hline 2002 & & $5.0000 \mathrm{E}+01$ & $1.4511 \mathrm{E}+03$ & $3.6507 \mathrm{E}+00$ & $1.0528 \mathrm{E}+08$ & & & \\
\hline 2003 & & $5.1161 \mathrm{E}+01$ & $1.4868 \mathrm{E}+03$ & $4.9007 \mathrm{E}+00$ & $1.4133 \mathrm{E}+08$ & & & \\
\hline 2004 & & $5.2570 \mathrm{E}+01$ & $1.5301 \mathrm{E}+03$ & $6.0008 \mathrm{E}+00$ & $1.7306 \mathrm{E}+08$ & & & \\
\hline 2005 & & $5.4414 \mathrm{E}+01$ & $1.5874 \mathrm{E}+03$ & $5.4120 \mathrm{E}-04$ & $1.2355 \mathrm{E}+03$ & & & \\
\hline 2006 & & $5.6236 \mathrm{E}+01$ & $1.6439 \mathrm{E}+03$ & $5.5200 \mathrm{E}-04$ & $1.3419 \mathrm{E}+03$ & & & \\
\hline 2007 & & $5.7886 \mathrm{E}+01$ & $1.6950 \mathrm{E}+03$ & $5.5180 \mathrm{E}-04$ & $1.4269 \mathrm{E}+03$ & & & \\
\hline 2008 & & $6.0204 \mathrm{E}+01$ & $1.7668 \mathrm{E}+03$ & $5.2160 \mathrm{E}-04$ & $1.5444 \mathrm{E}+03$ & & & \\
\hline 2009 & & $6.0000 \mathrm{E}+01$ & $1.7606 \mathrm{E}+03$ & $5.4175 \mathrm{E}-04$ & $1.6807 \mathrm{E}+03$ & & & \\
\hline 2010 & & $6.1000 \mathrm{E}+01$ & $1.7917 \mathrm{E}+03$ & $6.3370 \mathrm{E}-04$ & $1.8596 \mathrm{E}+03$ & & & \\
\hline 2011 & & $6.2891 \mathrm{E}+01$ & $1.8503 \mathrm{E}+03$ & $7.4530 \mathrm{E}-04$ & $1.9426 \mathrm{E}+03$ & & & \\
\hline 1992 & & $4.7504 \mathrm{E}+00$ & $-1.6494 \mathrm{E}+04$ & $1.7540 \mathrm{E}+01$ & $8.7642 \mathrm{E}+12$ & & & \\
\hline 1993 & & $4.7504 \mathrm{E}+00$ & $-1.6494 \mathrm{E}+04$ & & & & & \\
\hline 1994 & & $4.7505 \mathrm{E}+00$ & $-1.6494 \mathrm{E}+04$ & & & & & \\
\hline 1995 & & $4.7504 \mathrm{E}+00$ & $-1.6494 \mathrm{E}+04$ & & & & & \\
\hline 1996 & & $4.6005 \mathrm{E}+00$ & $-1.6494 \mathrm{E}+04$ & & & & & \\
\hline 1997 & & $5.0005 \mathrm{E}+00$ & $-1.6493 \mathrm{E}+04$ & & & & & \\
\hline 1998 & & $3.9004 \mathrm{E}+00$ & $-1.6494 \mathrm{E}+04$ & & & & & \\
\hline 1999 & & $4.1005 \mathrm{E}+00$ & $-1.6494 \mathrm{E}+04$ & & & & & \\
\hline
\end{tabular}




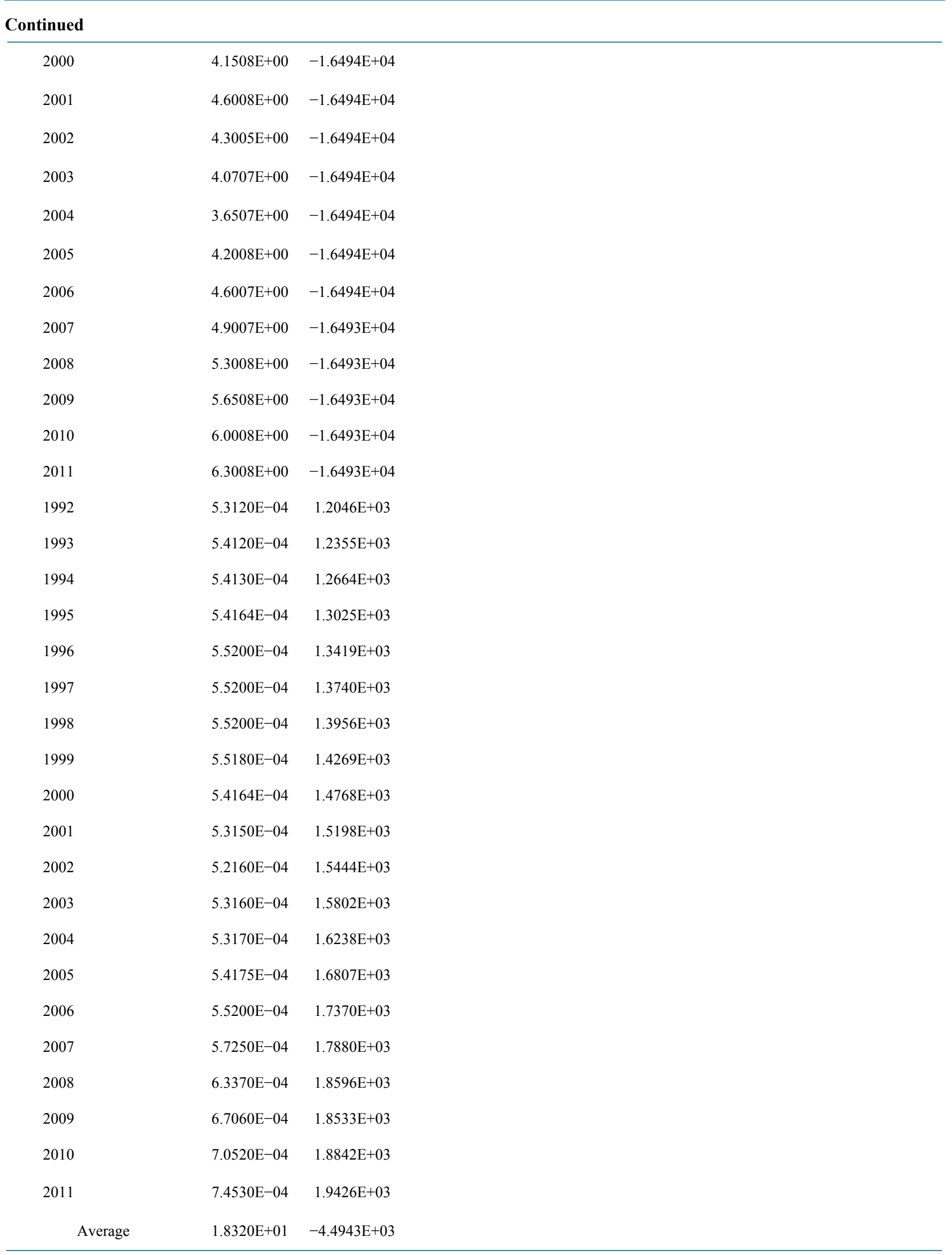


Table 3. The analyses.

\begin{tabular}{|c|c|c|}
\hline \multicolumn{2}{|c|}{ Variables } & 1. Solar; 2. Gas; 3. Nuclear \\
\hline $\begin{array}{c}\text { The } \\
\text { random } \\
\text { walk } \\
\text { hypothesis }\end{array}$ & $V R(q)=1$ & $\begin{array}{l}\text { The result of this test } V R(q)=0.97 \text { (actual) and }=0.99 \text { (estimated) emphasizes that the null } \\
\text { hypothesis } V R(q)=1 \text { indicates that the selected index of business sectors follows a random } \\
\text { walk. This means that the values of the sector are influenced by specific internal or external } \\
\text { factors that can be manipulated by individuals or other sectors. This can be asserted by the fact } \\
\text { that the main factors affecting the desalination process are not controlled by one or two entities. } \\
\text { The main factor is the desalination technology itself, where the utilization of refined high } \\
\text { resolution technologies such as the nanotechnology and material amalgamation led to the } \\
\text { production of highly refined purification schemes and temperature controlled piping systems. } \\
\text { Energy source utilization technology, for example is diverse where we have, in addition } \\
\text { to the three mentioned above, coal, oil, wind and other forms of hydroelectric energy sources. } \\
\text { In each of these power producing mechanisms the technology is advancing at a fast pace. } \\
\text { Fuel saving, emission controls and efficiency are major factors influencing decision makers. } \\
\text { Energy sources such as gas, nuclear, solar, etc. are another factor that can be influenced } \\
\text { by politics, delivery and distribution and related shipping safety, international relationships, } \\
\text { refining technology and more. Desalination technology is more independent than the energy } \\
\text { or the energy utilizing technologies. Due to the versatility of the energy techniques } \\
\text { employed for desalination and the diversity of the desalination mechanisms, it is that } \\
\text { such index does follow a random walk hypothesis. }\end{array}$ \\
\hline
\end{tabular}

Although $V R(q)=\sim 1$, it is possible the hypothesis is rejected returning $V R(q)<1$ which indicates that the related sectors are negatively serially correlated and in a sense in the process to correct a mature market. This interpretation is also possible. Desalination and its related energy sources and technologies have been around for a long time, and the market has gone through many changes and fluctuations technologically and financially. Another interpretation is the possibility that the sectors are approaching a stage in which a financial bubble is about to happen. This interpretation is unlikely since only a few countries are utilizing this technology extensively and the businesses and entities involved in the related technologies are diverse and versatile.

The interest-based financial potential indicates that the actual values have increased significantly over a period of twenty years for all the three variables by over one hundred percent in comparison to a future value as indicated in Tables 1-3,

Finance

by AP1, AP2, and AP3 respectively. The present value was calculated by taking the actual value of the first year, and multiplying by 2000 to get the cost of the 2 GJ plant and then financing over twenty years with a $3 \%$ interest, using the average relative interest in the US for similar projects. The changes in the actual values over twenty years indicate the significant business financial interest in this industrial sector and its potential future worth.

The relatively low variance variations despite the large changes and disparities in the actual cost-values indicate that the changes are gradual and paced. The difference in value between the variances and the covariance is due to the large disparity between the actual values of the three industrial energies.

The portfolio theory's risk assessment provides us with positive results. The direct solar energy desalination sector, despite its fluctuating data, is more stable in terms of its variation and the negative output is due to the data variations, and the fact that is not a major sector, where there does not exist a single large scale desalination plant anywhere in the world. Some small mediocrely designed plants exist in the US and Australia.

However, the gas-based desalination plants are a major factor in the seawater desalination industry. Although the risk associated with such sector is small, there exists very few gas-based large scale desalination plants and are almost all located in one area, Arabian peninsula, where gas is abundant and cheap. Gas is just like oil subject to political and

Risk Assessment 1. Portfolio risk estimated to be $17 \%$; 2. Portfolio risk is estimated to be $0.02 \%$; 3. Portfolio risk estimated to be $2 \%$ economic stability of the gas producing countries, and or the areas where gas is produced. Such volatility could make such venture very costly outside the middle east, although the safety of such projects could be in-doubt in case of a war in the area. Not to mention that the gas-based turbines are complex and hard to maintain which may exacerbate the situation.

Nuclear energy for desalination is becoming more popular due to the cost effectiveness of the nuclear energy on the long run and its larger risk assessment is due to the increasing variations in the cost of producing electricity through nuclear power, however nuclear power can be more cost-effective if utilized to produce both heat for desalination of seawater and to run electrical turbines for electrical energy. Although this sector is facing an expected snag, because of its diverse applications. Nevertheless, there is a new method for employing nuclear reactors that utilize radioactive elements with short-life cycles, and diminished capacity to make nuclear weapons. 
FW ranges from $7 \%$ to $9 \%$ of the actual annually changing per energy cost (Table 3 ). This indicates a successful endeavor despite the low interest rate. The solar desalination actual cost of the energy is lowest in comparison to the nuclear and gas powered methods. However, that is not necessarily enough to appreciate this scheme. The cost of such technique may be higher in other countries. Nations in the northern and southern hemisphere may not have enough solar radiation to generate enough heat, not to mention the sea-side ground elevation relative to seawater level [4]. Nations near the equator especially in desert areas may not have the appropriate geography to employ such approach, and altering the landscape maybe too costly.

\section{Technical Analysis}

This paper employs a number of analytical procedures and processes in order to reach an outcome that is gauged from different perspectives through diverse analyses. The following explains the process in an easy to read and understand scheme.

\subsection{The Methodology}

The total annual cost per million joules (TAC/MJ) for nuclear, gas and solar seawater desalination industries is employed as the main actual variable as the industrial investments' annual revenues; Table 1 is a demonstration of the solar industry's activity.

$R_{i}$ utilizing $R_{1}, R_{2}$ and $R_{3}$, for the industries mentioned above, respectively. The data is utilized to assess the viability of solar seawater desalination as a continuous source of drinking water. The actual data is estimated using the first order autoregressive model Equations (1)-(6) (Table 1) [9] [10]. Equation (7) is used to test for the stability and deviation of the explained and unexplained autoregressive model's variations between the actual and estimated variances (Table 1). Then using Equations (8)-(11), the variance ratio (VR) is calculated to test for the random walk hypothesis (Table 2). Finally, Equations (8) and (13), the heteroscedasticity asymptotic variance (HAV) and 15, the consistency form, to test for the market-earnings consistency, in this case growth or a bubble (Table 2). Equation (16) tests the estimated variables and variances for investment risks for the three industrial sectors. The equations mentioned above are listed in the order they are employed as follows:

$$
\check{R}_{i t}=\theta_{i}+\pi_{i} R_{i, t-1}+\varepsilon_{i, t}, \quad i=1, \cdots, n
$$

where $R_{i, t}=$ the values vector represented by the industrial return at time t. " $\theta_{i}, \pi_{i}=$ constants calculated using ordinary least squares model $\varepsilon_{i, t}=$ a noise random variable in the industrial-return variables, averaging zero with a value of 1 for standard deviation in bivariate dependent regression, which maybe more instrumental in economics sensitivity studies; overall can be eliminated in earnings estimates" [10]. Equation (1), puts more emphasis on regressive estimates of the actual values with emphasis on the so called unexplained disturbance (noise) for multivariate regression. This unexplained disturbance, in reality is an error that can be explained by the variation in the deviation of the estimated variance from that of the actual over the regression period. In this case, it is simplified by employing the time series periods and degrees of freedom to factor into the co-variances instead of using expected return coefficients. The coefficients in this equation correlate the independent variables.

$$
\begin{gathered}
\check{R}_{i t}=\theta_{i}+\pi_{i} R_{i, t-1}, \quad i=3,1 \\
\theta_{i}=\check{R}_{1}, \check{R}_{2}, \check{R}_{3} \text { and }-r\left(\sigma_{i} / \sigma_{j}\right) \check{R}_{1}
\end{gathered}
$$

(for solar desalination $i=3$ )

If $i=3,1$ then $\left(\sigma_{i} / \sigma_{j}\right)=\left(\sigma_{3} / \sigma_{1}\right),\left(\sigma_{1} / \sigma_{3}\right), i \neq j$, respectively.

$$
\begin{gathered}
\pi_{i}=r\left(\sigma_{3} / \sigma_{1}\right), \quad \text { for } i=3 \\
V\left(R_{i}\right)=\pi_{i}^{2} V\left(\check{R}_{i}\right)+V\left(\varepsilon_{i, t}\right)=r\left(\sigma_{i} / \sigma_{j}\right)^{2} V\left(\check{R}_{i}\right)+V\left(\varepsilon_{i, t}\right)
\end{gathered}
$$

Equation (5) can be employed for estimating variance of two variables, where $\left(\sigma_{i} / \sigma_{j}\right)$ are the variances of the separate industries however our case requires Equation (7) due to the extreme fluctuations of our industrial 
variables. Equation (2) estimates the actual variables' for two variables. In this process, as mentioned in the previous paragraph, the noise' standard deviation is 1 , and averaging zero which allows economists to exclude the disturbance, in this case, when estimating revenue. However, Equation (1) is more appropriate where the unexplained deviation is formulated by manipulating Equation (7). For example, Equation (6) is an example of a partial correlation coefficient where $r_{23}$ correlates the independent variables $R_{2}$ and $R_{3}$ a correlation coefficient for a third variable is utilized to compensate for the significant disparities in magnitude between the separate variables, So for $i=2, j=3, i \neq j$

$$
\pi_{i}=r_{i j}\left(\sigma_{i} / \sigma_{j}\right)=r_{32}\left(\sigma_{3} / \sigma_{2}\right) \& r_{31}\left(\sigma_{3} / \sigma_{1}\right)
$$

or vise-versa for the variance and correlation coefficients.

$$
\begin{aligned}
V\left(R_{i}\right) & =R^{2} V\left(\check{R}_{i}\right)+V\left(\varepsilon_{i, t}\right) \\
& =\left\{\left[V\left(\check{R}_{i}\right)(k-1)\right] /\left[V\left(\check{R}_{i}\right)(k-1)+(n-k) \operatorname{cov}\left(\check{R}_{i}, \check{R}_{a}\right)\right]\right\} V\left(\check{R}_{i}\right)+V\left(\varepsilon_{i t}\right) \\
& =\left\{\left[(k-1)\left(\sigma_{i}^{2}\right)\right] /\left[(k-1)\left(\sigma_{i}^{2}\right)+(n-k)\left(r_{i a} \sigma_{i} \sigma_{a}\right)\right]\right\} V\left(\check{R}_{i}\right)+V\left(\varepsilon_{i t}\right),
\end{aligned}
$$

In this equation we can see the coefficient of determination $R^{2}$ which is a variance ratio used primarily to simplify explaining the variance deviation between the actuals and their estimates, and is instrumental in calculating the noise [10] [11]. In this equation $n$ and $k$ are population degrees of freedom to balance the variance covariance estimates of the ratios. The following Equation (8) is the population variance ratio relating the variables on the basis of their degrees of freedom to accentuate the sampling population variability, where the fluctuation in Equation (9) is examined in relationship to Equation (10), where the sampling $y$ is used to amplify the ratios for the mean sample-calculation of $\breve{Y}$ Equations (8), (11), and (13)-(15).

$$
\begin{gathered}
V R(k)=\left(\sigma^{2}(k) / \sigma^{2}(1)\right) \\
\sigma^{2}(k)=1 / k(n k-k+1)(1-(k / n k))^{*} n k \sum_{t=k}\left(y_{t}-y_{t-k}-k \check{Y}\right)^{2} \\
\sigma^{2}(1)=1 /(n k-1) n k \sum_{t=1}\left(y_{t}-y_{t-1}-k \check{Y}\right)^{2} \\
\check{Y}=1 / n k\left(y_{n k}-y_{0}\right) \\
V(k)=2(2 k-1)(k-1) / 3 k(n k)
\end{gathered}
$$

Equation (12) is a sampling degree of freedoms ratio of the non-heteroscedastic variance. Where Equation (13) is similar to Equation (8) with more emphasis on the heteroscedasticity of the variance variables; in this case, not only is the sampling of the population is important, but also the diversity of the variables.

$$
\begin{gathered}
V^{*}(k)=\sum_{m=1}^{k-1}[2(k-m) / k]^{2} \frac{\left[n k \sum_{t=m+1}\left(y_{t}-y_{t-1}-\ddot{y}\right)^{2}\left(y_{t-m}-y_{t-m-1}-\ddot{y}\right)^{2}\right]}{\left[n k \sum_{t=m+1}\left(y_{t}-y_{t-1}-\ddot{y}\right)^{2}\right]^{2}} \\
Z(k)=(V R(k)-1) / V(k)^{-(1 / 2)} \\
Z^{*}(k)=(V R(k)-1) / V^{*}(k)^{-(1 / 2)} \\
V(R)=\eta^{2} V\left(R_{1}\right)+g^{2} V\left(R_{2}\right)+d^{2} V\left(R_{3}\right)+2 \eta g r \sigma_{1} \sigma_{2}+2 \eta \operatorname{dr} \sigma_{1} \sigma_{3}+2 g d r \sigma_{2} \sigma_{3}
\end{gathered}
$$

Equations (14) and (15) relate the variance ratios with homoscedasticity and heteroscedasticity, respectively. Equation (16) is the portfolio selection theory formula [10] [12] [13]; it provides the industrial investment risk assessment employing the variables and variances' estimates, where $\eta, g$ and $d$ represent the industrial percentage coefficients. 


\subsection{The Abstract Analysis}

The solar-heat plant's maintenance's cost encompasses cleaning the reservoirs' walls and surfaces, the condensers and evaporators piping along with the solar fields' metallic surfaces and concrete inner ducts. The cleaning is done through flush-rinsing the surfaces, ducts and pipes with forced water and using water suctioning to help clear the surfaces and linings of precipitants. The cost is estimated to be $\$ 1$ per square meter plus $\$ 1$ per square meter for coating the solar fields' metal surfaces with less than one millimeter of tar. The total surface area including the ducts and piping is estimated to be $10 \mathrm{Mm}^{2}$ (million square meters). The total cost $=10 * 1+4$ (total tar surface-area) $* 1=\$ 14 \mathrm{M}$; the cost pricing employs the market's whole-sale maintenance pricing in Saudi Arabia during the late Nineties. The cost per square meter $=14 / 10=\$ 1.4$ per square meter and the cost of the energy produced $=14 \mathrm{ex} 6 /(2.96 * 4 \mathrm{ex} 6)=1.18 \mathrm{per} \mathrm{MW}$, where the energy produced $=\sim 2.96 \mathrm{MJ} / \mathrm{m}^{2}$ and the heat collectors area is 4 million square meters [4]. The inflation index between 1995 and 2013 has a low of 98 with a high of 148. Using an average approximation we get 2.8 as the annual (consumer price index) average inflation, with the year 1999 as the base index for the actual data in Table 1. Table 3 sums up the results of the analyses of the three industries and their feasibility on the basis of the tests done above.

\section{Conclusion}

Sadly, as it may be, some sort of a hidden agenda to elicit large profits may be in the works in the minds of many business executives looking to tap into this futuristically very profitable undertaking. Such mind-set is acceptable and encouraged, and eventually mankind will benefit from such unsettling agenda. The analysis above demonstrates that seawater desalination is a viable business sector with a very profitable outlook. The utilization of direct solar energy is a definite plus technically and economically. The low cost of employing solar energy signifies its potential value. Although land cost has never been mentioned in the costing of this example, due to the government control over public land in Saudi Arabia, however, public land throughout the world can be leased at reasonable rates when utilized for public benefits. The low construction and maintenance cost of the solar energy for desalination of seawater outweighs legal, legislative or political obstacles. It is easy to build easy to maintain and unlike the other two options, is not subject to market or political fluctuation and wrangling, respectively.

\section{References}

[1] Joseph, O.S. (2011) Comparative Assessment of Coal-Fired and Nuclear Power Plants. Rensselaer Polytechnic Institute, Hartford.

[2] Hogue, M.T. (2012) A Review of the Costs of Nuclear Power Generation. Bureau of Economic and Business Research, David Eccles School of Business, University of Utah, Salt Lake City.

[3] Al-FulaijHala, F. (2011) Dynamic Modeling of Multi Stage Flash (MSF) Desalination Plant. Thesis Submitted for the Degree of Doctor of Philosophy, Department of Chemical Engineering, University College London (UCL), London.

[4] Ashry, M.H. (2013) A Large Scale Desalination of Sea Water by Solar Energy Using an Unconventional Seawater Collectors Scheme. Proceedings of the 12th International Conference on Information \& Knowledge Engineering, IKE13, Las Vegas, 22-25 July 2013.

[5] Kaplan, S. (2008) Power Plants: Characteristics and Costs. CRS Report for Congress.

[6] Khamis, I. (2013) Overview of Nuclear Desalination Technologies \& Costs. Department of Nuclear Energy, Division of Nuclear Power, IAEA International Atomic Energy Agency.

[7] Díaz-Caneja, J. and Fariñas, M. Cost Estimation Briefing for Large Seawater Reverse Osmosis Facilities in Spain. RIDESA, Ramón Rubial n², 48950 Erandio, Spai.

[8] http://www.economywatch.com/economic-statistics/country/Saudi-Arabia/

[9] Barth, J., Kraft, J. and Wiest, P. (1975) Portfolio Theoretic Approach to Industrial Diversification and Regional Employment. Journal of Regional Science, 15, 9-15. http://dx.doi.org/10.1111/j.1467-9787.1975.tb01127.x

[10] Ashry, M.H. (2008) Income and Employment in Single Sector Economies: Growth Through Diversification in Saudi Arabia. Department of Engineering Management and Systems Engineering, Sc.D. Thesis, The George Washington University, Washington DC.

[11] Squalli, J. (2005) Working Paper No. 05-01: Are the UAE Financial Markets Efficient? EPRU, Zayed University, Abu Dhabi and Dubai. 
[12] Andersen, T.G., Bollersev, T. and Das, A. (2001) Variance-Ratio Statistics and High-Frequency Data: Testing for Changes in Intraday Volatility Patterns. The Journal of Finance, 56, 305-327.

[13] Markowitz, H.M. (1959) Portfolio Selection, Efficient Diversification of Investments. Yale University Press, Newhaven and London. 
Scientific Research Publishing (SCIRP) is one of the largest Open Access journal publishers. It is currently publishing more than 200 open access, online, peer-reviewed journals covering a wide range of academic disciplines. SCIRP serves the worldwide academic communities and contributes to the progress and application of science with its publication.

Other selected journals from SCIRP are listed as below. Submit your manuscript to us via either submit@scirp.org or Online Submission Portal.
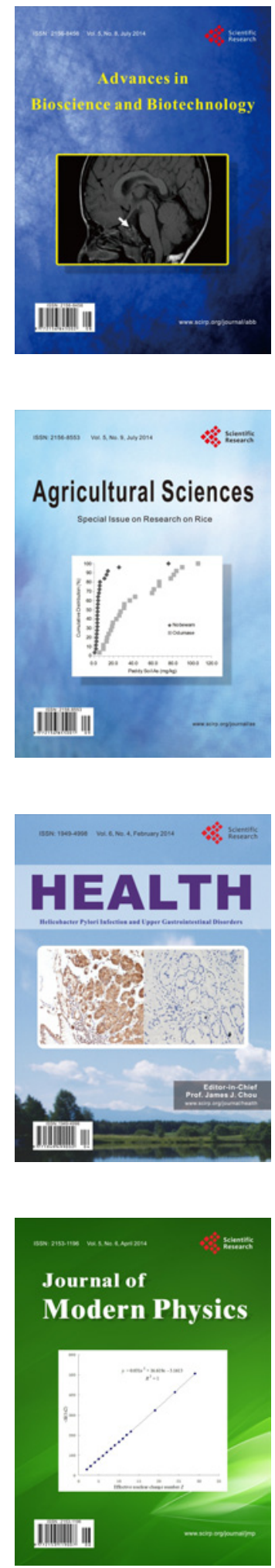
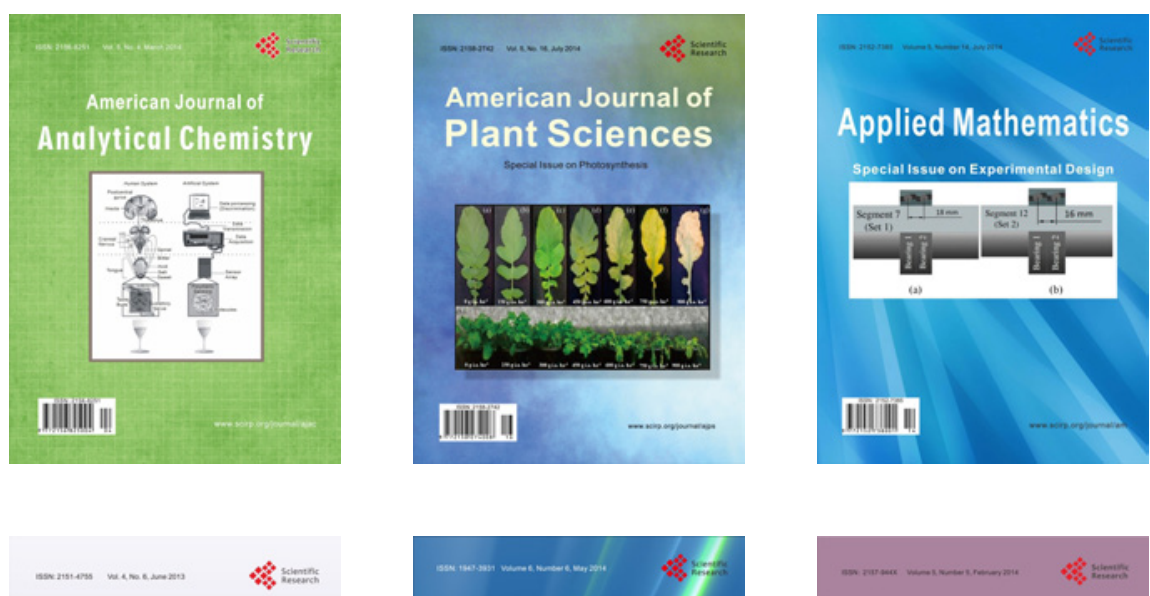

Creative Education
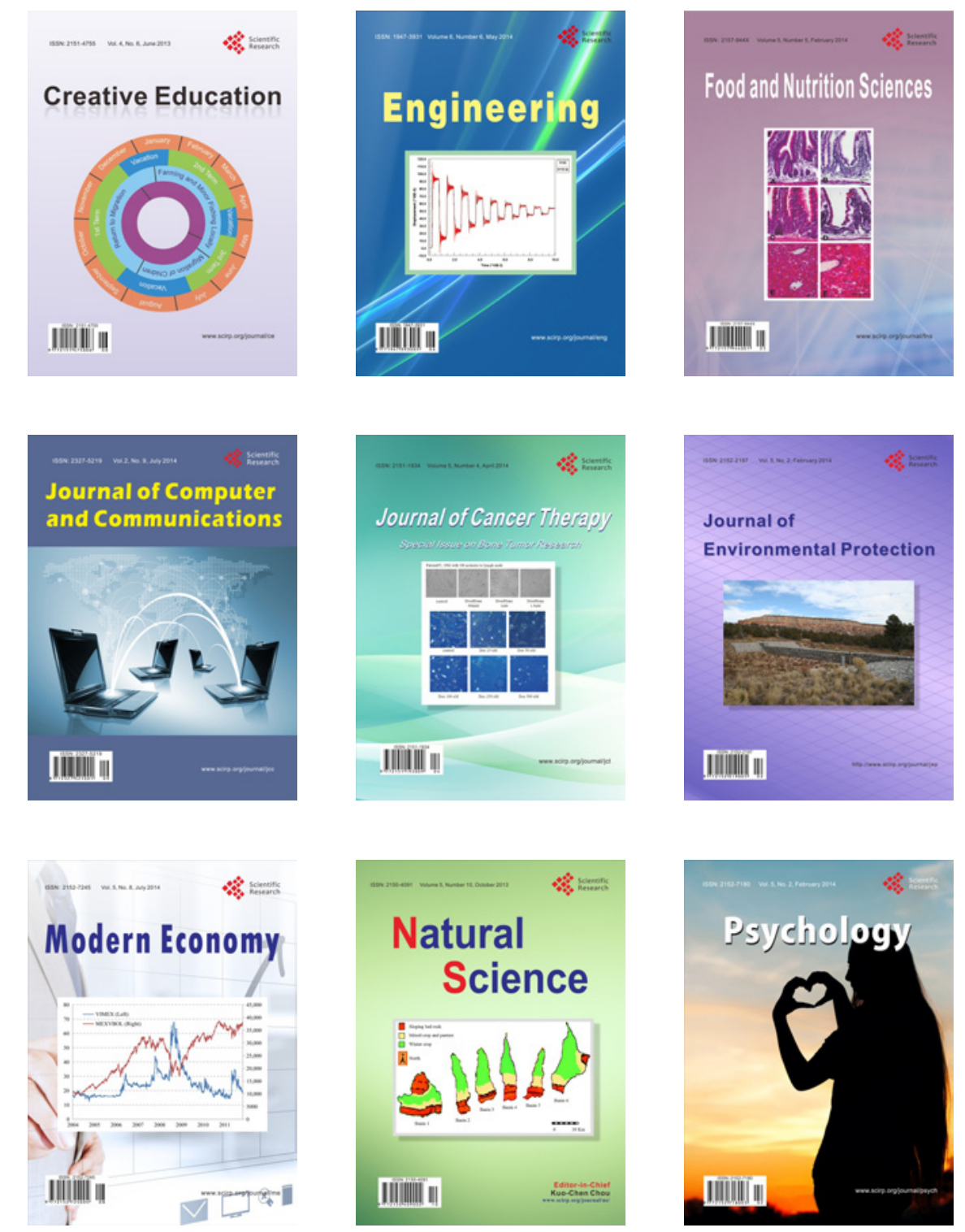